\title{
Design of a Wide-band Printed Antenna using a Genetic Algorithm on an Array of Overlapping Sub-patches
}

\author{
Matthias John \\ Technological University Dublin, matthias.john@tudublin.ie \\ Max Ammann \\ Technological University Dublin, max.ammann@tudublin.ie
}

Follow this and additional works at: https://arrow.tudublin.ie/engschececon

Part of the Electrical and Computer Engineering Commons

\section{Recommended Citation \\ John, M. \& Ammann, M. (2006) Design of a wide-band printed antenna using a genetic algorithm on an array of overlapping sub-patches. IEEE International Workshop on Antenna Technology Small Antennas and Novel Metamaterials, New York, March 6-8, 2006, doi:10.1109/IWAT.2006.1608983}

This Conference Paper is brought to you for free and open access by the School of Electrical and Electronic Engineering at ARROW@TU Dublin. It has been accepted for inclusion in Conference papers by an authorized administrator of ARROW@TU Dublin. For more information, please contact arrow.admin@tudublin.ie, aisling.coyne@tudublin.ie,gerard.connolly@tudublin.ie. Funder: Science Foundation Ireland

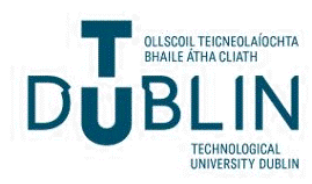




\title{
DESIGN OF A WIDE-BAND PRINTED ANTENNA USING A GENETIC ALGORITHM ON AN ARRAY OF OVERLAPPING SUB-PATCHES
}

\author{
M. John and M. J. Ammann \\ Centre for Telecommunications Value-chain Driven Research \\ Dublin Institute of Technology \\ School of Electronic and Communications Engineering \\ Kevin Street, Dublin 8, Ireland \\ Tel.: 003514024716 \\ Email: matthias.john@student.dit.ie
}

\section{Introduction}

Printed planar rectangular monopoles have shown to be useful wideband antennas for communication systems [1]. These antennas can be easily integrated due to fabrication on printed circuit boards. Attempts to enhance bandwidth with shorting posts or bevels have been successfully made [2].

Optimization by Genetic Algorithms yield great potential in finding non-conventional solutions and has been successfully applied to patch antennas $[3,4]$. The printed monopole antenna described in this paper was designed and optimized using a genetic algorithm.

In previous use of sub-patches in GA implementations, problems on lattice points were reported [5]. Such problems are overcome by letting the sub-patches overlap to ensure electrical connection on the corners of these patches.

\section{Antenna Geometry}

Figure 1(a) shows the reference rectangular plate monopole antenna which was optimized by classic parameter sweep optimization [1]. For the genetic algorithm design, the substrate, groundplane and feedline dimensions remain the same. The rectangular plate is replaced by a cell array of $8 \times 8$ metallic elements. The cells are placed by the GA. The principle of the GA design is illustrated in Figure 1(b).

The microstrip-fed GA patch monopole is printed on one side of FR4 substrate; the groundplane is located on the back. The dimensions of the substrate are $l=90 \mathrm{~mm}$ and $w=50 \mathrm{~mm}$. The groundplane is $50 \mathrm{~mm}^{2}$. The microstrip feedline $\left(\mathrm{w}_{f}=2.5 \mathrm{~mm}\right)$ is exited by an SMA connector. The dimensions of the GA patch are $h_{p}=30.25 \mathrm{~mm}$ and $w_{p}=30.25 \mathrm{~mm}$. The substrate is $1.52 \mathrm{~mm}$ thick and the metallization thickness is 35 microns. The dimensions of the reference plate monopole is $h_{p}=20 \mathrm{~mm}$ by $w_{w}=30 \mathrm{~mm}$.
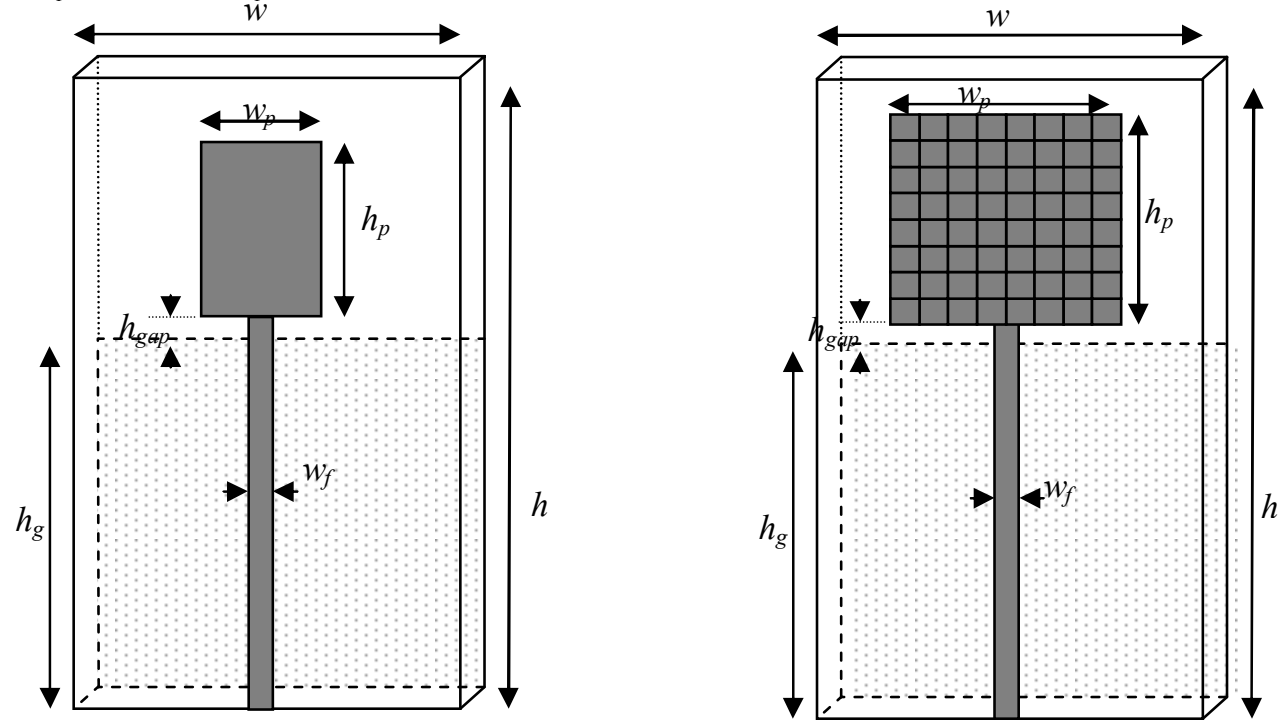

Figure 1. (a) Geometry of the reference rectangular plate monopole.

(b) Radiating patch replaced by $8 \times 8$ cells 
The patch monopole consists of 64 metallic elements which are $h_{c}=4 \mathrm{~mm}$ by $w_{c}=4 \mathrm{~mm}$ in size. Previous designs use geometry refinement techniques to remove $\left(\begin{array}{ll}0 & 1 \\ 1 & 0\end{array}\right)$ or $\left(\begin{array}{ll}1 & 0 \\ 0 & 1\end{array}\right)$ constellations to overcome problems at lattice points, where two sub-patches touch at the corner [5]. In this design the sub-patches overlap by $l_{o}=0.25 \mathrm{~mm}$ to ensure electrical contact in such constellations in the fabricated antenna. The principle of the overlapping element design is shown in Figure 2. Due to overlapping, the resulting maximum dimensions of the patch are $h_{p}=30.25 \mathrm{~mm}$ by $w_{p}=30.25 \mathrm{~mm}$.
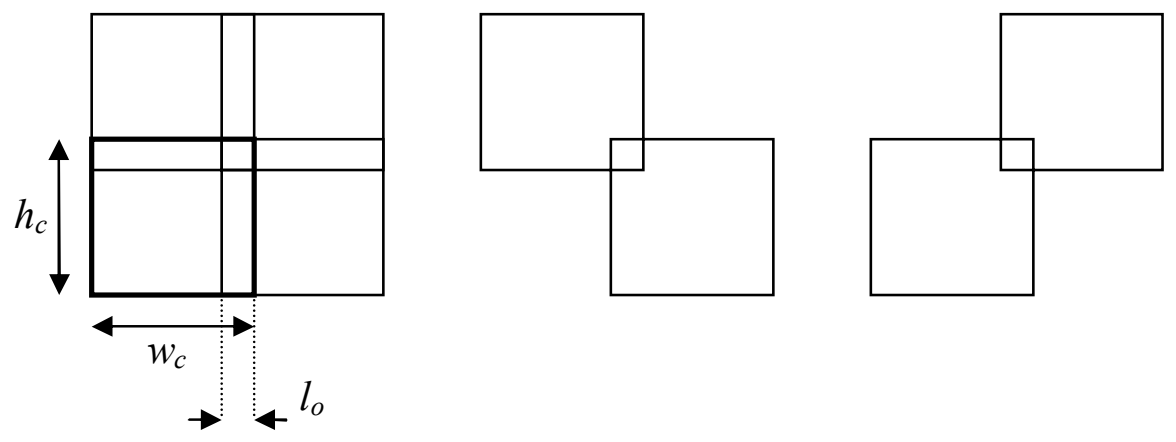

Figure 2. (a) Geometry of overlapping neighboring elements

$(\mathrm{b}, \mathrm{c})$ Lattice point constellations $\left(\begin{array}{ll}1 & 0 \\ 0 & 1\end{array}\right)$ and $\left(\begin{array}{ll}0 & 1 \\ 1 & 0\end{array}\right)$

\section{Genetic Algorithm and Simulation}

Each metallic element of the radiating patch can be switched 'on' or 'off' by the genetic algorithm. Figure 1(b) shows all elements switched 'on'.

The entire patch is encoded into a 64 bit binary string which represents the chromosome. Therefore, $2^{64}$ different patches exist in the search space. The GA starts with a population of randomly generated patches and then modifies the patch shape through selection, crossover and mutation according to their performance. The GA is implemented in MatLab. The performance of each patch generated by the GA is evaluated using CST Microwave Studio. The goal is defined as the sum of all $\mathrm{S}_{11}$ values that exceed $-10 \mathrm{~dB}$, to achieve the maximum bandwidth between $0-10 \mathrm{GHz}$.

The population size was set to 40 and evolved over 20 Generations. The peak and average performance of each generation is shown in Figure 4. It can be seen that both values converge to a maximum of 8.70 $\mathrm{GHz}$.

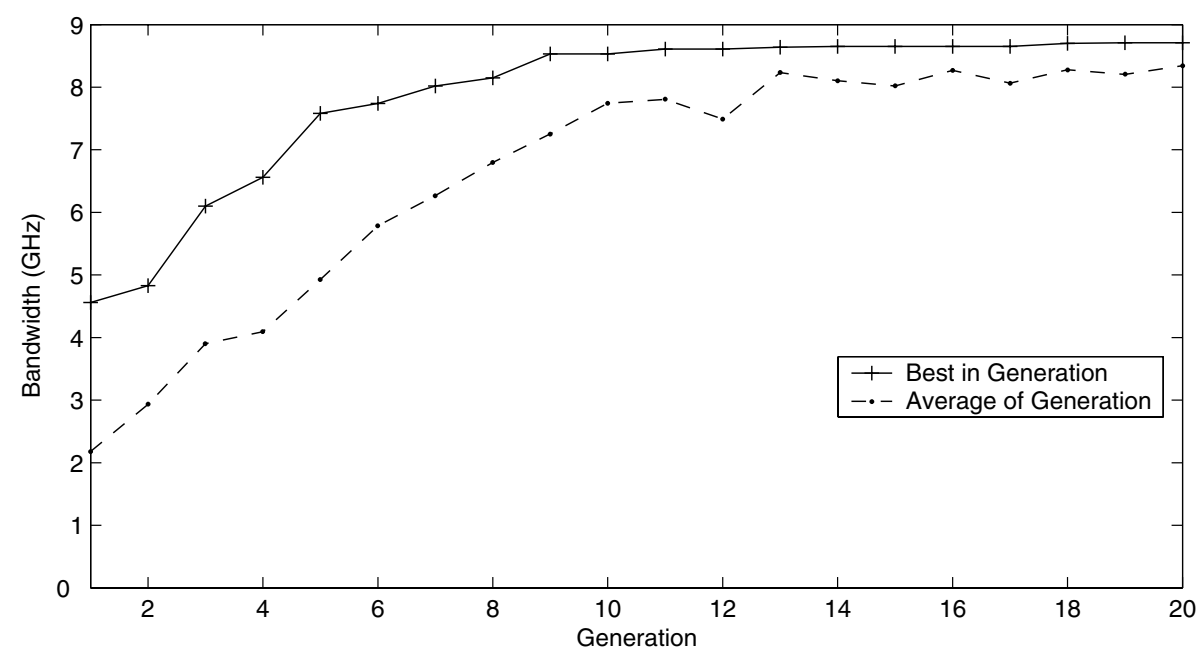

Figure 3. Peak and average performance of generations 


\section{Results}

The designs with the widest bandwidth and their return loss are shown in Figure 4 and Figure 5. The simulated return loss for the first patch is greater than $10 \mathrm{~dB}$ from $1.36 \mathrm{GHz}$ up to $10 \mathrm{GHz}$. Thus, an impedance bandwidth ratio of 7.35:1 is achieved.
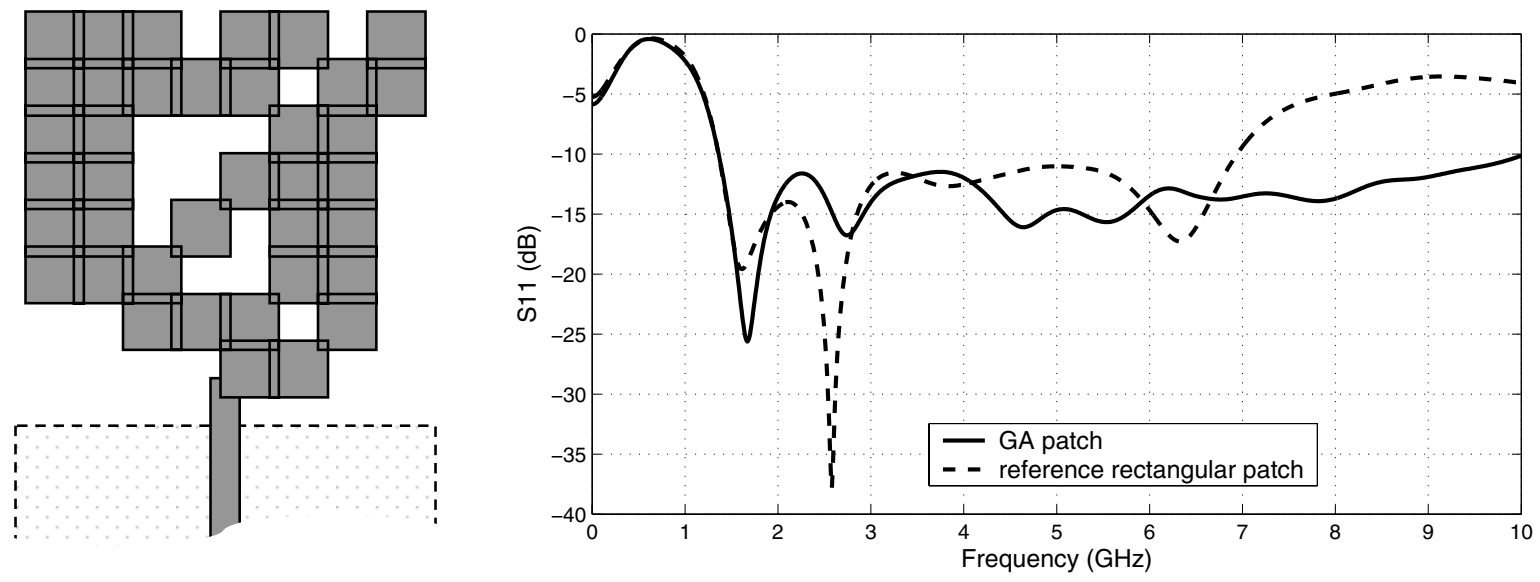

Figure 4. (a) Design generated by GA (b) Simulated return loss in comparison with reference rectangular plate monopole

The second design comprises an isolated parasitic element which is not connected to the monopole, but improves the performance. The lower edge frequency is reduced from $1.36 \mathrm{GHz}$ to $1.30 \mathrm{GHz}$. The return loss is greater than $-10 \mathrm{~dB}$ from $1.30 \mathrm{GHz}$ to $10 \mathrm{GHz}$. The impedance bandwidth ratio for this design is 7.69:1.
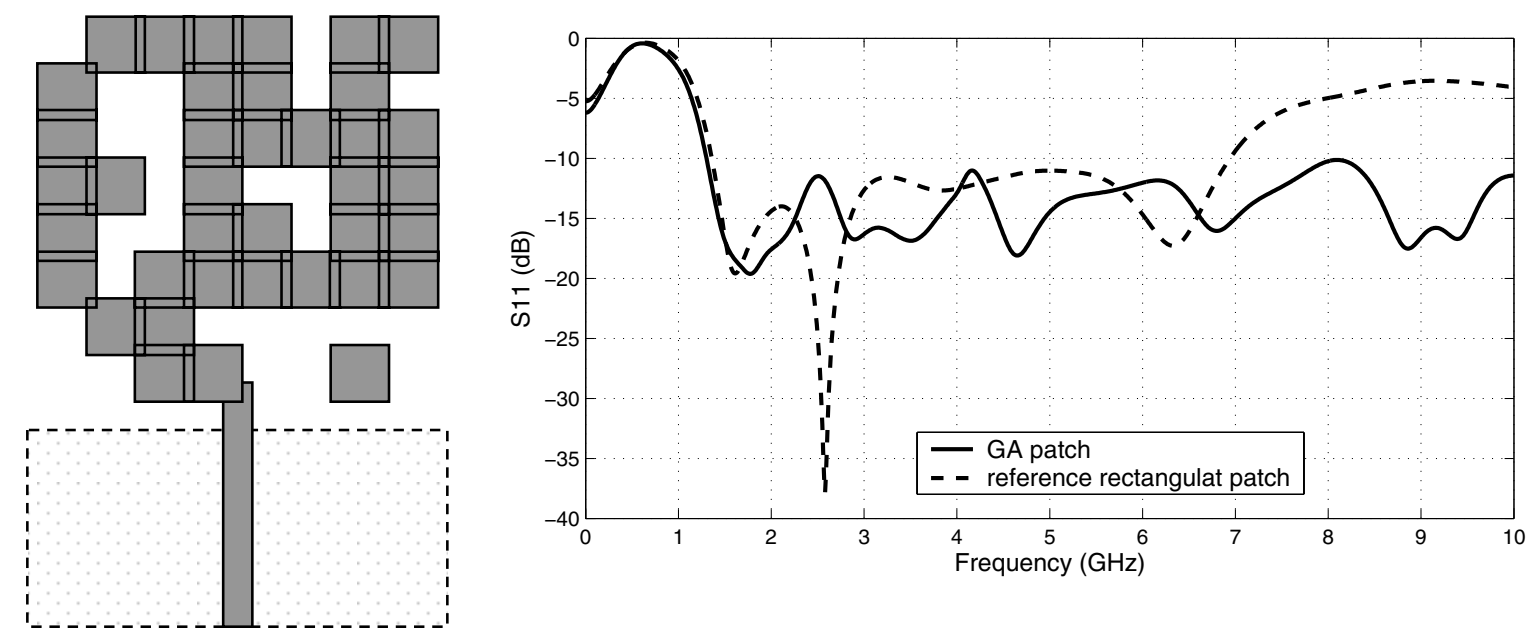

Figure 5. (a) Design with parasitic element generated by GA (b) Simulated return loss in comparison with reference rectangular plate monopole 
The maximum gain is $2.5 \mathrm{dBi}$ at $1.68 \mathrm{GHz}, 3.8 \mathrm{dBi}$ at $2.73 \mathrm{GHz}, 2.0 \mathrm{dBi}$ at $4.62 \mathrm{GHz}$ and $4.8 \mathrm{dBi}$ at $7.89 \mathrm{GHz}$. Simulated radiation patterns at these frequencies are shown in Figure 6.

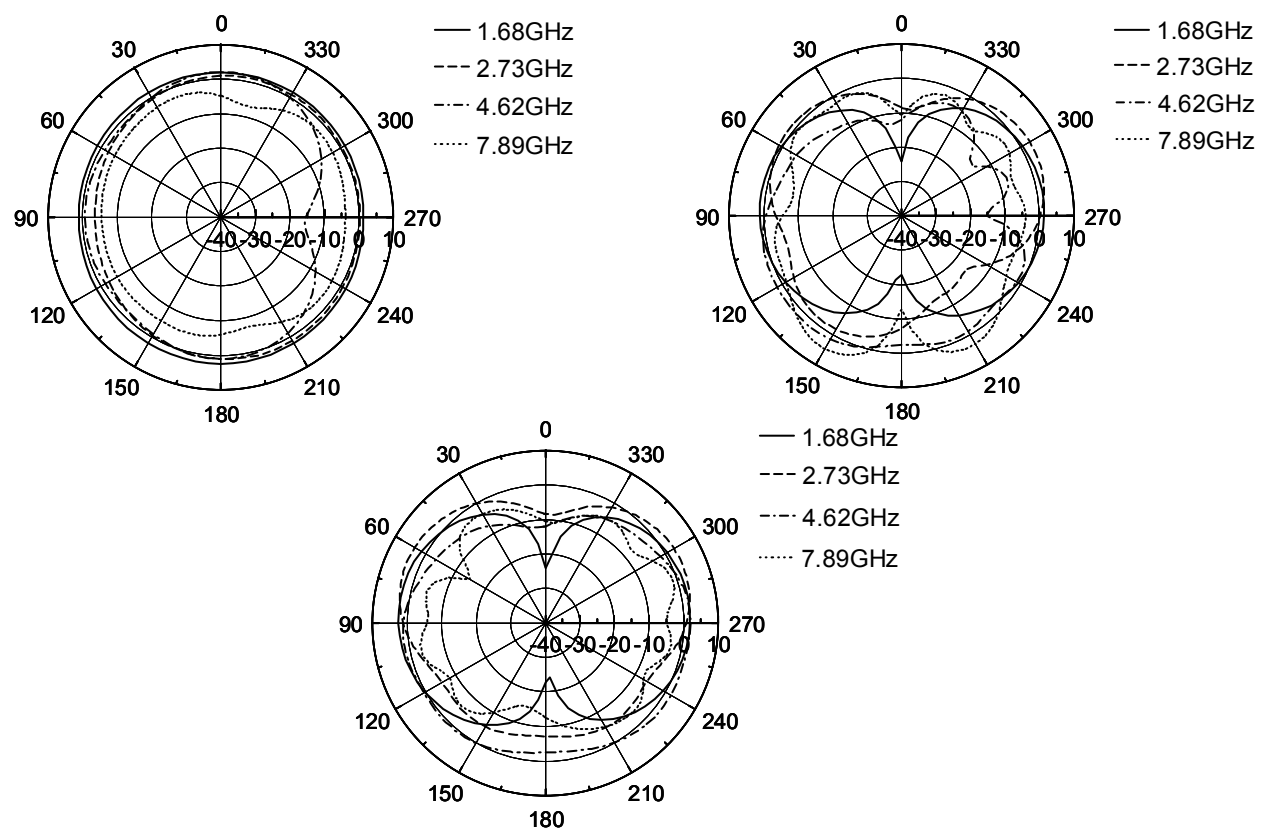

Figure 6. Simulated radiation patterns for the (xy), (yz) and (xz) planes.

\section{Conclusion}

GA-optimized patch shapes for printed monopoles were investigated. Overlapping sub-patches were used in the design to improve electrical contact on the corners of these sub-patches. The results were compared to a previous rectangular monopole [1]. With the GA optimization technique, the bandwidth was improved by $63 \%$ over the rectangular patch.

\section{Acknowledgements}

This work was supported by Science Foundation Ireland.

\section{References}

[1] M. John and M. J. Ammann, "Optimisation of Impedance Bandwidth for the Printed Rectangular Monopole Antenna," Microwave and Optical Technology Letters, vol. 47(2), pp. 153-154, Oct. 2005.

[2] M. J. Ammann and Z. N. Chen, "Wideband monopole antennas for multiband wireless systems," IEEE Antennas Propagat. Mag., no. 45, pp. 146-150, 2003.

[3] F. J. Villegas, T. Cwik, Y. Rahmat-Samii, and M. Manteghi, "A Parallel Electromagnetic Genetic-Algorithm Optimization (EGO) Application for Patch Antenna Design," IEEE Trans. Antennas Propagat., vol. 52, no. 9, pp. 2424-2435, Sept. 2004.

[4] H. Choo, A. Hutani, L. C. Trintinalia, and H. Ling, "Shape optimization of broadband microstrip antennas using genetic algorithm,” IEE Electronics Lett., vol. 36, no. 25, pp. 2057-2058, Dec. 2000.

[5] M. Ohira, H. Deguchi, M. Tsuji, and H. Shigesawa, "Multiband Single-Layer Frequency Selective Surface Designed by Combination of Genetic Algorithm and Geometry-Refinement Technique," IEEE Trans. Antennas Propagat., vol. 52, no. 11, pp. 2925-2931, Nov. 2004. 